\title{
Assessing the Potential Impacts of the Grand Ethiopian Renaissance Dam on Water Resources and Soil Salinity in the Nile Delta, Egypt
}

\author{
Sherien Abdel Aziz ${ }^{1,2}$, Martina Zeleňáková ${ }^{3, *}$, Peter Mésároš ${ }^{4}$, Pavol Purcz ${ }^{4}$ and \\ Hany Abd-Elhamid 5,6 \\ 1 Higher Institute of Engineering \& Technology, Zagazig, Ministry of Higher Education, Zagazig 44519, Egypt; \\ sherien.abdelaziz@eng.zu.edu.eg \\ 2 Ministry of Water Resources \& Irrigation, Zagazig 44519, Egypt \\ 3 Department of Civil Engineering, Faculty of Engineering, Technical University of Kosice, Kosice 04200, \\ Slovakia \\ 4 Department of Construction Technology and Management, Faculty of Engineering, Technical University of \\ Kosice, Kosice 04200, Slovakia; peter.mesaros@tuke.sk (P.M.); pavol.purcz@tuke.sk (P.P.) \\ 5 Department of Water \& Water Structures Engineering, Faculty of Engineering, Zagazig University, \\ Zagazig 44519, Egypt; h.f.abdelhamid@zu.edu.eg \\ 6 Civil Engineering Department, College of Engineering, Shaqra University, Dawadmi 11911, Saudi Arabia \\ * Correspondence: martina.zelenakova@tuke.sk
}

Received: 31 October 2019; Accepted: 19 November 2019; Published: 10 December 2019

\begin{abstract}
Several studies have reported that the construction of the Grand Ethiopian Renaissance Dam (GERD) could have severe effects on the water resources in downstream countries, especially Egypt. These effects include changes in surface water level, groundwater levels in shallow and deep aquifers, saltwater intrusion, and increases in soil salinity, which could affect crop yields. This paper assesses the potential impacts of the GERD on the Nile Delta, Egypt. It includes the effects of reducing surface water levels (SWL) and changing the crop patterns at the groundwater levels (GWL), in addition to the effect of cultivating crops that consume less water on soil salinity. A pilot area is selected in the east of the Nile Delta for the assessment. The results of the study revealed that GWL is directly proportional to SWL. Comparing the case study of 2012, when SWL was reduced by $50 \%$, the GWL decreased from $5.0 \mathrm{~m}$ to $2.0 \mathrm{~m}$. After adjustment, the crop patterns from rice to other crops decreased the GWL to $1.30 \mathrm{~m}$. Additionally, the results showed that there is a significant relationship between soil salinity and crop patterns. Soil salinity increased during the cultivation of the Delta with non-rice crops, such as grapes. Salinity increased from $0.45 \mathrm{~S} / \mathrm{m}$ after 10 years of simulation to $0.48 \mathrm{~S} / \mathrm{m}$. This estimation highlights the undesirable effects of the GERD on Egypt's water resources, soil salinity, crop yields, and national income.
\end{abstract}

Keywords: GERD; surface water levels; groundwater levels; crop pattern; soil salinity

\section{Introduction}

Surface water is considered the main source of water in Egypt. The Nile River was and still is the main source of surface water that flows in the canal's networks all over Egypt. The Nile River supplies the required quantities of water for different purposes, such as irrigation, domestic applications, industry, and navigation purposes. Egypt is a downstream country among the eleven countries of the Nile Basin, and its annual share of the River Nile water is about 55.5 BCM (billion cubic meters) according to the 1959 treaty. Egypt's share did not change until recently, while the population has multiplied by nearly three times. Surface water is not enough in many areas, particularly during 
the periods of maximum demand in the summer. In many parts of the Nile Delta, the amounts of surface water are not sufficient, especially for agricultural and domestic requirements. Thus, users are forced to compensate for this shortage illegally, in most cases from a shallow aquifer by digging wells that penetrate the shallow aquifer at different depths according to the thickness of the upper clay layer in those regions. This withdrawal from the shallow aquifer is sustainable as a solution for the shortage of surface water, where the shallow aquifer is characterized as a renewable aquifer. The study in [1] reported that the shallow aquifer in the Nile Delta is recharged by excess irrigation water, rainfall, and seepage from canals and drainage networks. The authors in [2] estimated numerically the infiltrated surface water to groundwater in the western Nile Delta, Egypt by 28.1 million $\mathrm{m}^{3} /$ day.

The study in [3] concluded that there is a strong relationship between groundwater levels (GWL) and surface water levels (SWL) by analyzing both measured and collected data. This means that the problem of surface water shortages due to the construction of the Grand Ethiopian Renaissance Dam (GERD) will affect both surface and groundwater. The authors in [4] deduced that the Aswan High Dam (AHD) will reach its minimum operational level during four consecutive years, which in turn will affect the water supply to Egypt, as the preservation of the GERD occurs during dry years. The study in [5] numerically assessed the effects of the GERD on Egyptian water resources and concluded that the maximum allowable reduction in Egypt's water share should not be more than 5-15\%. The authors in [6] discussed the causes of the Egyptian rejection of the GERD using qualitative methods that depended on secondary data, such as articles, journals, e-news, e-books, and other literary sources. The results showed that Egypt's share of the Nile water will be reduced, which in turn will affect Egypt's stability.

The study in [7] proved that reducing water levels in the canals would affect the GWL, but discharging from groundwater is more effective, depending on three scenarios, which were simulated by the MODFLOW software. The authors in [8] recommended changing or modifying the policies applied by the Ministry of Water and Water Resources (MWRI) to overcome the negative impacts of the GERD on Egypt; otherwise, there will be many types of severe problems. The results were obtained by using a mathematical model to create different scenarios of operation. The study in [9] stated that the GERD is causing a severe crisis between Ethiopia and Egypt, so alternative solutions were proposed, such as the efficient use of water by re-utilizing drainage and municipal water and wasting less surface water. The authors in [10] reported that the expected amount of water saved using the proposed strategies adopting a stochastic method to estimate the risks of the GERD on Egypt exceeds the expected losses caused by the GERD, at 12.1 BMC.

The study in [11] showed that filling the GERD reservoir in three and six years required reducing the groundwater extraction rates from the Nile Delta aquifer by $60 \%$ and $40 \%$, respectively, to maintain the freshwater body in the Nile Delta aquifer; this study developed a numerical model using SEAWAT to simulate the groundwater flow and solute transport while operating the dam. Although the GERD is a great national project for the Ethiopians, it has negative side effects on downstream countries, especially Egypt. Therefore, these effects should be measured by evaluating their impact. When examining any side effects of an applied project, the estimates become adequate, such as the authors in [12], who made an EIA for sub-surface drainage projects in Egypt by modifying the Food and Agriculture Organization (FAO) Check List to be suitable for measuring the resulting impacts; this project operated for a number of years.

The study in [13] evaluated the effectiveness of an EIA in Slovakia by using a survey. A questionnaire was used to obtain data, which was then analyzed to obtain information about the current state of the EIA/SEA (Strategic Environmental Assessment), the EIA/SEA practice, and the EIA in the future as a step to improve the performance of the EIA in Slovakia. Based on previous studies, it can be predicted that any shortage in the supply of surface water could affect the recharging of the shallow water aquifer, which will subsequently affect the GWL.

In 2011, the Ethiopian Government announced it was starting a project to produce electricity through a hydroelectric dam called The Renaissance Dam, which has been constructed on the Blue 
Nile River, at a distance of $45 \mathrm{~km}$ from its eastern border with Sudan. The capacity of the upstream storage lake is $74 \mathrm{BCM}$. The GERD will produce 6000 Megawatts, (MW). Thus, the upstream countries will control the Nile flow to downstream countries. Consequently, the crisis of the dam filling is of great concern to downstream countries. The estimated storage time ranged from three to seven years. During this storage period, the Egyptian share of water could be exhausted. This will affect different sectors in Egypt, especially the agriculture sector, which consumes 84\% of Egypt's water resources that come (mainly) from the Nile River. This problem is exacerbated by the fact that Egypt applied decisive decisions to prevent reducing the potential impacts from the construction and operation of the GERD. The most serious decision was preventing voracious crops, mainly rice, from being cultivated in some regions and reducing the cultivated areas in other regions. This decision could reduce the amount of excess irrigation water that infiltrates into the shallow aquifer, which could affect the GWL and increase soil salinity.

This paper aims to estimate the potential impacts of the GERD on the Nile Delta, Egypt. Some of these impacts have been recognized, such as the decrease of the SWL in irrigation canals, which is remarkable based on the sectors involved in the SWL. Factors like shortages in the GWL related to shortages in the SWL should be carefully estimated, as the GWL in the shallow aquifer is a basic alternative to the shortage of SW in many regions in the study area. The other factor is the crop patterns. These crops include non-voracious crops, which means less water leading to less recharge of the groundwater aquifer, including deep and shallow aquifers. Non voracious crops go further and could damage the soil properties in the Delta, which is famous for its high quality, because less irrigation water means less soil leaching, which could increase the salinity of the soil that has accumulated over time, thereby creating undesirable amounts of salts that are not suitable for the cultivation process; this is considered an indicator for economic deterioration in the Egyptian agriculture sector. Therefore, an estimation was performed for the three main problems by evaluating and measuring the effects on GWL due to: (i) the expected shortage in surface water, (ii) changing the crop patterns, and (iii) evaluating the deterioration that could affect soil salinity.

\section{Materials and Methods}

The expected problems arise from the construction and operation of the GERD, the effect of SWL on GWL, and the effect of changing the crop patterns for both GWL and soil salinity, which should be measured by suitable tools to provide a realistic estimation of the GERD's influence on Egypt, mainly the Egyptian Delta. Consequently, the materials and methods satisfy these goals.

\subsection{Materials}

The materials include the selection of the pilot area and all the required data owned and required to perform simulations of the aforementioned problems. These data include a study area description, the climate, the surface water system, the groundwater system, and the interaction between the surface and groundwater.

\subsubsection{The Study Area}

The study area is a part of the Nile Delta, which began to suffer from the negative impacts of the GERD. The selected area represents many areas in the Nile Delta which have the same conditions and are subject to the same problems in the north of Egypt. In the Eastern Nile Delta, many farmers suffer from a shortage of surface water. Groundwater is used as a unique alternative to meet the demands for water. A clear example of this is the area located in the Sharkia governorate (Abo Kabear city), which is $22 \mathrm{~km}$ from the capital of Sharkia Governorate (Zagazig City). Figure 1 shows the location map of the selected area, which is about 84.000 acres. The longitude and latitude of the study area are $30^{\circ} 43^{\prime} 30^{\prime \prime} \mathrm{N}$ and $31^{\circ} 40^{\prime} 17^{\prime \prime} \mathrm{E}$, respectively. The study area has been extremely affected by the shortage of surface water. This shortage has played a large role in reducing the recharge to the groundwater aquifer. 
This shortage has also had a fundamental role in the implementation of new policies in cultivation, such as reducing the cultivation of rice in the Delta.

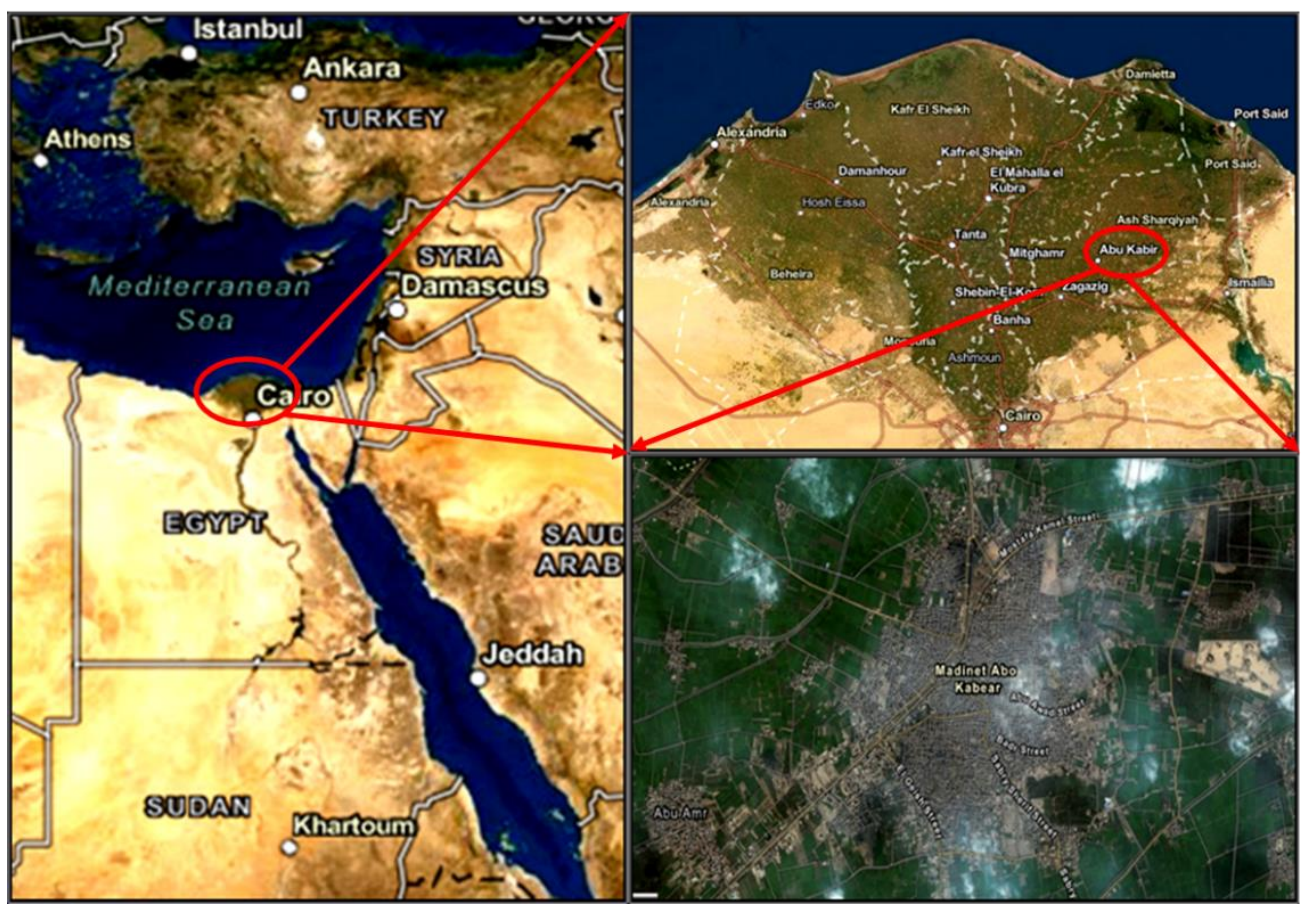

Figure 1. Location map of the study area.

\subsubsection{The Climate}

The study area is located in an arid region. In summer, the climate is hot, dry, and rainless. In winter, the climate is mild with little rain. The mean daily maximum temperature during the summer is $37^{\circ} \mathrm{C}$. This temperature falls to $12^{\circ} \mathrm{C}$ in the winter. The annual rainfall is estimated to be $51 \mathrm{~mm} /$ year.

\subsubsection{The Groundwater System in the Study Area}

The Nile Delta aquifer system is generally a complex groundwater system which is leaky and has upper semi-permeable boundaries. The study area belongs to a semi-confined aquifer which is covered with Holocene silt and clay (semi-confined) with thicknesses varying from 0 to $20 \mathrm{~m}$. The aquifer is underlain by Pliocene marine clay (lower impermeable boundary) and consists of three layers. The first layer is aquitard (clay cap) with a thickness of $10 \mathrm{~m}$. This layer represents the layer of discharge for shallow wells. The second layer is the aquifer consisting of sand and gravel with clay lenses. Its thickness in the study area is $400 \mathrm{~m}$. This layer is the source of groundwater for the deep wells. The third layer is the aquiclude (sticky clay). Its thickness in the study area is $390 \mathrm{~m}$, as shown in Figure 2 [14]. 


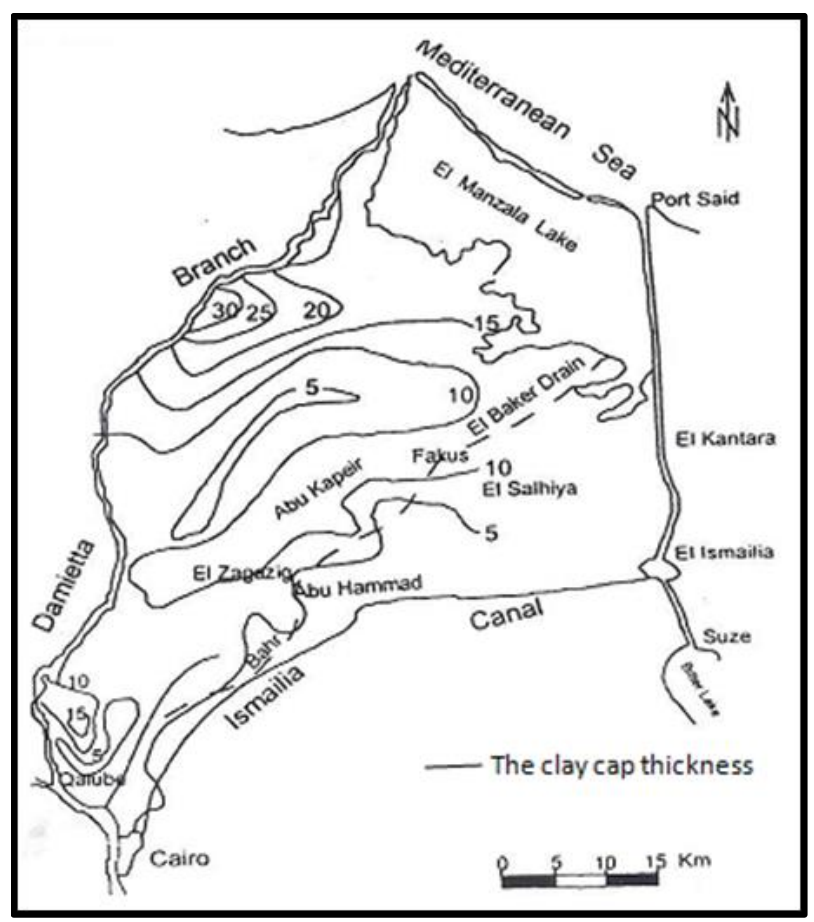

Figure 2. The thickness of the clay cap [14].

\subsubsection{The Surface Water System in the Study Area}

Water in canals provides the main source of surface water in the selected area. Although the amount of annual rainfall is estimated to be $51 \mathrm{~mm} /$ year, which is very small, this quantity was taken into consideration in the simulation [1], where the rain precipitates in either the land or canals. In canals, rain becomes a part of the surface water system. Egypt is characterized by its unique irrigation system because its irrigation system is a net system that starts from the canals with the highest position. The Nile River has the highest position in the irrigation network-A rayah (a type of canal in Egypt that has a higher position than the main canal) extends from the main canal to the branch canal and ends with a meska (a very small canal used in irrigation in farms). A meska is the only way to irrigate as it is forbidden to irrigate from other types of canals. A total of 52 canals comprise the irrigation network in the area, which is considered the only recharger to the groundwater aquifer, neglecting the small amount of precipitation. The Elsadey and Elmesalamia canals are the two main canals in the study area.

\subsubsection{The Interaction between the Surface Water and Groundwater Systems}

The interaction between the surface water system, including irrigation network plus rainfall, is represented by the leakage through the upper soil layer of the aquifer. This leakage provides the recharge to the aquifer in this area. In addition, the irrigation water exceeds the plant's needs, through which the system disposes of the water via two methods. The first method occurs naturally through the soil, but the excess water in the root zone flows under gravity and capillary fringes to the shallow aquifer under the cultivated area. The second occurs artificially through the sub-surface and surface drainage system to lower the groundwater in the plants' root zones to prevent the waterlogging of cultivated land. The discharged groundwater from the selected area assumes the form of random and illegal wells. These wells consist of wells for irrigation, domestic, and drinking purposes. The amounts of extracted groundwater were estimated through a questionnaire and field investigation. An inventory was made for domestic and irrigation wells in the study area in 2012, where the number of wells used to compensate for the shortage in irrigation water was 898 wells, with extraction equaling $10,800 \mathrm{~m}^{3} /$ day. On the other hand, the number of wells used to compensate for the shortage in water required for 
domestic purposes was 35,230 wells used by $49 \%$ of the city (the population in 2012 was 393,991 inhabitants) [15].

\subsection{Methodology}

The methodology entails the selection of an appropriate numerical model. We chose MODFLOW, which is a good instrument for the simulation process. The numerical model input data require information such as canals' cross-section areas, soil properties, aquifer characteristics, and soil salinity. The current methodology depends on the application of the appropriate numerical model (MODFLOW) to simulate the groundwater flow in the study area and to highlight the impact of the construction of the GERD on the selected study area. The methodology includes the application of the MODFLOW to assess three effects of the GERD:

I. The effect of reducing Egypt's share from the Nile River's water on the surface water levels in canals and its subsequent effect on groundwater levels in the shallow aquifer.

II. The effect of changing the crops from voracious crops to non-voracious crops on groundwater levels in the shallow aquifer

III. The effect of changing the crops from voracious crops to non-voracious crops on soil salinity.

\subsubsection{Numerical Model (MODFLOW)}

MODFLOW code was used to simulate the selected area and all its characteristics while taking into consideration the interaction between SW and GW. Each subsequent step in the simulation required a specified type of data, as follows.

The aquifer in the study area consists of three layers. The storage parameters for the three layers are shown in Table 1. The storativity $\left(\mathrm{m}^{-1}\right)$ is presented in the second column, and the ratio of the drained volume of water to the total volume, which is called specific yield or Sy, is expressed in the third column. The fourth and fifth columns present the total porosity and the effective porosity, respectively, which are the volume ratios (dimensionless). The model input data include the model grid, wells, soil properties, and boundary conditions. The size of the grid was chosen to be almost square, so the domain is divided into 61 rows and 45 columns, to obtain a nearly squared cell. The cell size is $401.5 \mathrm{~m} \times 401.5 \mathrm{~m}$, and the depth is divided into three layers. The hydraulic conductivity taken in the $x$ and $y$ directions is 0.25 and $0.025 \mathrm{~m} /$ day in the third direction for the first layer of the aquifer (the clay cap).

Table 1. The storage parameters of the study area.

\begin{tabular}{ccccc}
\hline Layer & $\mathbf{S}_{\mathbf{s}}$ (Specific Storage) $\mathbf{( m}^{\mathbf{- 1}}$ ) & $\mathbf{S}_{\mathbf{y}}$ (Specific Yield) (-) & $\mathbf{P}_{\mathbf{t}}$ (Total Porosity) (-) & $\mathbf{P}_{\text {eff }}$ (Effective Porosity) (-) \\
\hline aquitard & $20.34 \times 10^{-4}-25.59 \times 10^{-4}$ & $0.06-0.2$ & $0.34-0.57$ & $0.01-0.39$ \\
aquifer & $1.28 \times 10^{-4-} 10.2 \times 10^{-4}$ & $0.1-0.3$ & $0.25-0.53$ & $0.18-0.43$ \\
aquiclude & $10^{-2-} 10^{-4}$ & $0.01-0.1$ & $0.34-0.57$ & $0.01-0.18$ \\
\hline
\end{tabular}

The boundary conditions required for the irrigation canal network, which included SWL, bed level, bed width, and conductance, were assigned using the River package in MODFLOW. Additional pumping wells were also applied in the simulation, including domestic and irrigation wells as mentioned in the interaction between the surface and groundwater systems. The model calibration showed a high agreement between the GWL and the observed wells in the reference state, to which the next simulations are compared [1]. The reference state was the year 2012, before the GERD had any effect on Egypt. The three factors examined in this study are described as follows.

\subsubsection{Effect of Reducing the Surface Water Level on Groundwater}

The first case was used to evaluate the changes that could happen to the GWL of the shallow aquifer due to a decrease in the SWL after operation of the GERD. This case was performed through 
different scenarios. The results of all scenarios were compared with the current case to assess the expected changes. This simulation includes the water levels in the canals in 2017 and all the study area characteristics that are required for MODFLOW to obtain the associated GWL, such as soil properties, aquifer characteristics, and SWL in irrigation canals. Five scenarios for reducing the surface water level and its impact on groundwater levels in the aquifers are considered in the study. These scenarios include a reduction in the surface water levels by $10 \%, 20 \%, 30 \%, 40 \%$, and $50 \%$ based on previous studies according to the time of filling the reservoir. The performed scenarios adopted to assess the expected changes could, in reality, happen to the SWL in canals due to the operation of the GERD, which will, in turn, affect the GWL in the study area. The results are compared with the current case to highlight the effects of the GERD on the shallow aquifer and evaluate the acceptable changes according to the water needs in the study area.

\subsubsection{Effect of Changing the Crop Pattern on Groundwater}

The crop patterns are changed due to new policies in such areas to reduce the amount of water required for the agricultural sector, which in turn reduces the infiltrated amount of irrigation water to the shallow aquifer that comes from excess irrigation water, where water that exceeds the plant's needs infiltrates the aquifer. This is classified as the second aquifer recharger source after seepage from the irrigation canal network. One of the important goals of adopting a policy to use less water in irrigation is to reduce or prevent the cultivation of crops that consume large amounts of water, such as rice. Furthermore, the changes in the second recharger source of the shallow aquifer deserve to be evaluated. Replacing rice with other crops could reduce the infiltration rate, so a comparison between the previous crop patterns, which primarily include rice, and the latest crop patterns could illustrate the reduction amount when recharging the aquifer by changing the GWL. MODFLOW is used to simulate areas with crop patterns containing rice and the same areas without rice. This was done by changing the recharge. The recharge rate is not often measured at a site; rather, it is assumed to be a percentage of the precipitation. The average annual precipitation in Egypt is estimated to be $51 \mathrm{~mm} /$ year. The recharge is taken as a percentage of precipitation and typically ranges from $5 \%$ to $20 \%$, depending on different factors, including land use and vegetation type, surface topography, and soil cover material. In this study, all these factors are constant except the vegetation [16]. Thus, the results of the two cases were compared to show the difference in GWL due to changing the crop patterns in the study area.

\subsubsection{Effect of Changing the Crop Pattern on Soil Salinity}

Replacing crops that voraciously consume water with crops that consume less water is an obvious way to ameliorate the crisis of surface water shortage after the construction and operation of the GERD. However, changing crop patterns affects the soil's properties, particularly salinity. Crops that consume large amounts of water not only have economic benefits but are also cultivated to improve soil properties. The large amounts of water consumed by these types leached into the soil, especially in areas near the Mediterranean Sea (North Egypt). Soil properties have a negative effect on reducing (or even preventing) the cultivation of these crops, as salinity could increase, leading to a deterioration in soil properties. This damaged soil productivity also has an extremely negative economic return. The authors in [17] reported that land productivity is reduced if soil salinity surpasses the allowable limits for each crop. Hence, it was necessary to evaluate the cultivation of different types of crops on soil salinity. Five scenarios for grapes, squash, melons, maize, and rice were performed to obtain the soil salinity after cultivation. Each of the previous crops is an example of a category of plants. Each category has different daily water demands. Grapes have the least daily water consumption among the elected crops ( $4.55 \mathrm{~mm} /$ day), while rice is ranked first in daily water consumption $(7.80$ $\mathrm{mm} /$ day). The daily water consumption of squash, melons, and maize rests between grape and rice. MODFLOW is used in the simulations for these cases. The study in [1] estimated the electric conductivity (EC) in the study area by $4.40 \mathrm{~S} / \mathrm{m}$, where EC is a good indicator of salinity [18]. 


\section{Results}

The results of the three Egyptian items expected to be affected by the construction and operation of the GERD are discussed as follows.

\subsection{Assessing the Effect of Reducing the Surface Water Level on Groundwater}

In this regard, comparisons are made between the proposed cases of a shortage in SWL in the Egyptian canal and a base case. The base case has no impact from the GERD.

\subsubsection{The Base Case}

MODFLOW is used to simulate the same pilot area by the year 2012 to determine the GWL in the study area for the base case. The study in [1] simulated this base case by the year 2012, with significant returns for the estimation of GWL in the absence of the GERD effect. This base case is compared with the other proposed cases (cases accompanied by the effect of the GERD), to estimate changes relevant to GWL in a part of the Egyptian Delta. In the contour map of GWL for the base case shown in Figure 3, which ranged from 5.8 to $3.5 \mathrm{~m}$ (4.65 $\mathrm{m}$ as an average value), most groundwater levels are equal to or greater than $5 \mathrm{~m}$. The subsequent calibration of the GWL for the base case resulted in a good agreement between the observed GWL in the study area and the calculated GWLs. The maximum difference in the observed and calculated water heads was acceptable and evaluated by $0.029 \mathrm{~m}$ at one well (City well). Moreover, the model sensitivity for the parameters involved in the simulation proceeded to sort the results affected by changes in parameters. The model sensitivity was measured for the hydraulic conductivity, specific storage, specific yield, grid dimensions, and conductance between canal boundaries and beneath the soil. These measurements were highly convergent.

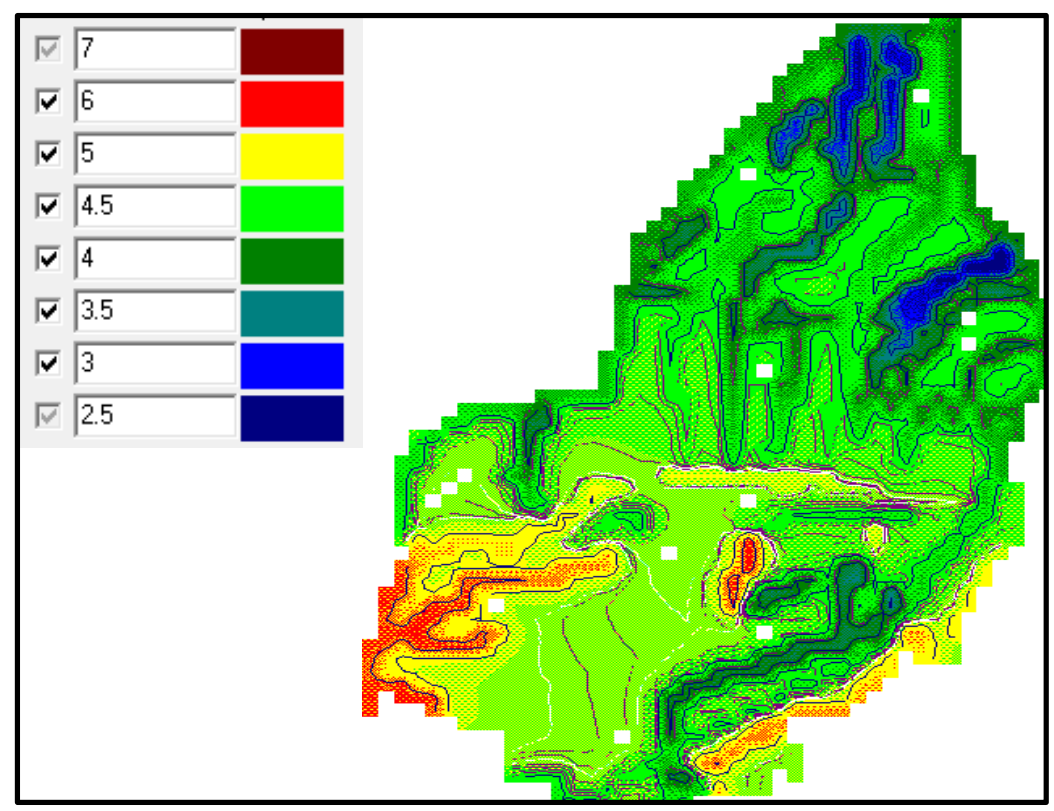

Figure 3. The contour map of the groundwater level for the base case.

\subsubsection{The Proposed Cases}

The different scenarios for reducing SWL and its effects on GWL are simulated using MODFLOW. The results show a change in GWL by decreasing SWL in irrigation canals during the supposed scenarios, relative to the previously studied case, by the year 2012 (base case). The results of the proposed scenarios comparing the base case, shown in Figure 4, displayed a 10\% reduction of SWL, while GWL decreased from $4.65 \mathrm{~m}$ (in the base case) to more than $4 \mathrm{~m}$. The scenario of reducing the SWL by $20 \%$ resulted in lowering the GWL between 3 and $4 \mathrm{~m}$, while a shortage of SWL by $30 \%$ 
could reduce GWL to $3 \mathrm{~m}$. The scenario of a $40 \%$ surface water shortage gave a GWL between 3 and $2 \mathrm{~m}$. The lowest GWL was found for a 50\% shortage in surface water ( 3 to $2 \mathrm{~m}$ ), indicating that the groundwater table for $2 \mathrm{~m}$ is greater than that for $3 \mathrm{~m}$. Figure 4 shows the groundwater levels in the simulated area for the different proposed scenarios. Here, a reduction in surface water level has a clear effect on the GWL in the shallow aquifer.

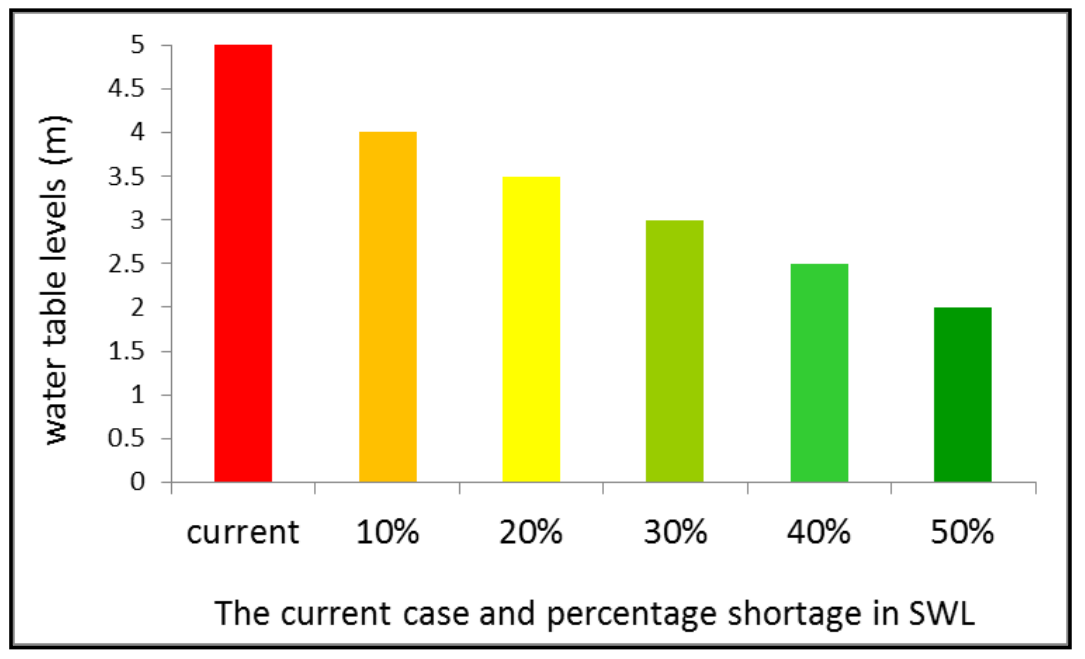

Figure 4. The groundwater level (GWL) due to reducing surface water level (SWL).

Figure 5 presents the relation between the groundwater levels in the simulated area and the percentage of reduction in the SWL in irrigation canals. A trend line could also express the relation between shortages in SWL and the relevant GWL; all the probables of the trend line had a high correlation factor $(R)>0.7$ (Table 2). In the least case, Equation (1) has an $R$ of 0.9272 . This relation could be more simply expressed as a linear equation (Equation (1)). Equation (1) could be verified by applying it to other areas and comparing the results.

$$
\mathrm{Y}=-0.5714 \mathrm{x}+5.3333
$$

where $\mathrm{x}$ is the percentage of reduction in $\mathrm{SWL}$, and $\mathrm{y}$ is the GWL.

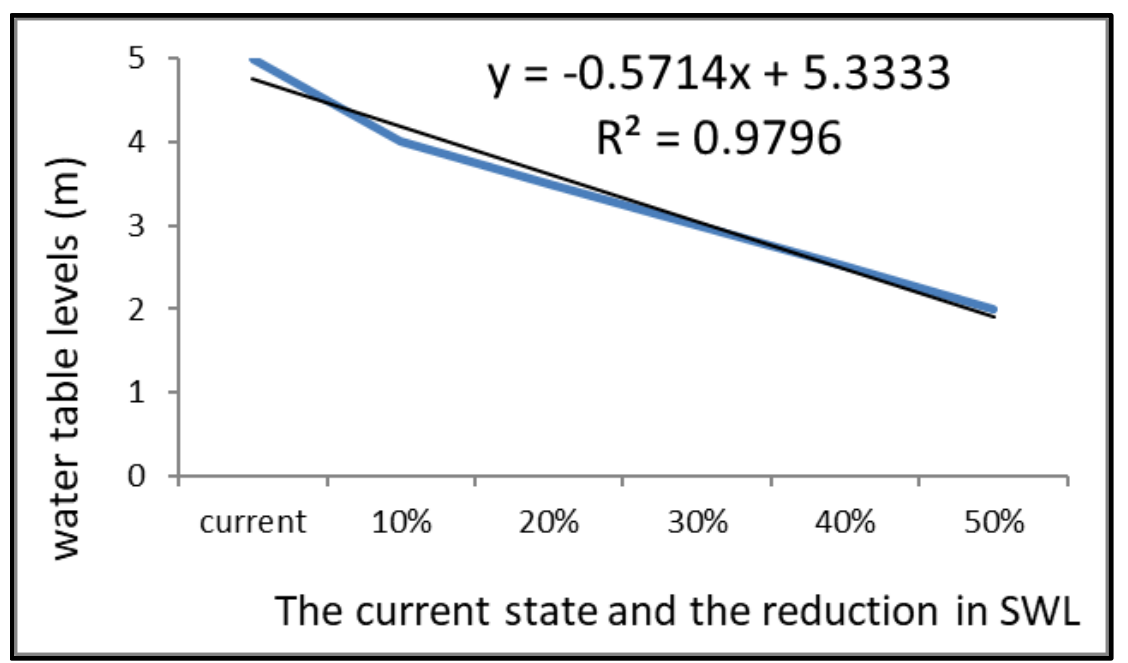

Figure 5. The relevance between GWL and the reduction in SWL in the study area. 
Table 2. The portable equations and their correlation factors.

\begin{tabular}{cccccc}
\hline Equation Type & Exponential & Linear & Logarithmic & Polynomial & Power \\
\hline $\begin{array}{c}\text { Correlation } \\
\text { factor }\end{array}$ & 0.9938 & 0.9796 & 0.9824 & 0.9923 & 0.9272 \\
\hline
\end{tabular}

\subsection{Assessing the Effect of Changing the Crop Pattern on Groundwater}

Studying the effects of changing recharge due to changing the crop pattern and its results were done using two scenarios. The first scenario involved cultivating the area with rice; the aquifer received the maximum recharge from excess irrigation water. After thirty years, the GWL increased annually. In contrast, the second scenario involved cultivating the area with non-rice crops, which consume minimal amounts of water. In this case, the GWL decreased to $4.6 \mathrm{~m}$ after thirty years of operation and then became stable at this value, as shown in Table 3. A comparison between the groundwater level and cultivation of rice and non-rice crops is shown in Figure 6, which illustrates a link between GWL and the time for both rice and non-rice crops. The results show a strong relationship between GWL and the cultivation of rice for both the short- and long-term. The GWL was directly proportional to time for the first fifteen years; then, it attained stability at forty years $(\mathrm{GWL}=4.60 \mathrm{~m})$ for the non-rice crops.

Table 3. The average GWL (m) for both scenarios.

\begin{tabular}{cccccccccccc}
\hline Year & One & $\mathbf{1 0}$ & $\mathbf{2 0}$ & $\mathbf{3 0}$ & $\mathbf{4 0}$ & $\mathbf{5 0}$ & $\mathbf{6 0}$ & $\mathbf{7 0}$ & $\mathbf{8 0}$ & $\mathbf{9 0}$ & $\mathbf{1 0 0}$ \\
\hline Rice & 4 & 4.7 & 4.9 & 5 & 5.1 & 5.25 & 5.4 & 5.5 & 5.7 & 5.8 & 5.9 \\
Non-rice crop & 4 & 4.6 & 4.55 & 4.6 & 4.6 & 4.6 & 4.6 & 4.6 & 4.6 & 4.6 & 4.6 \\
\hline
\end{tabular}

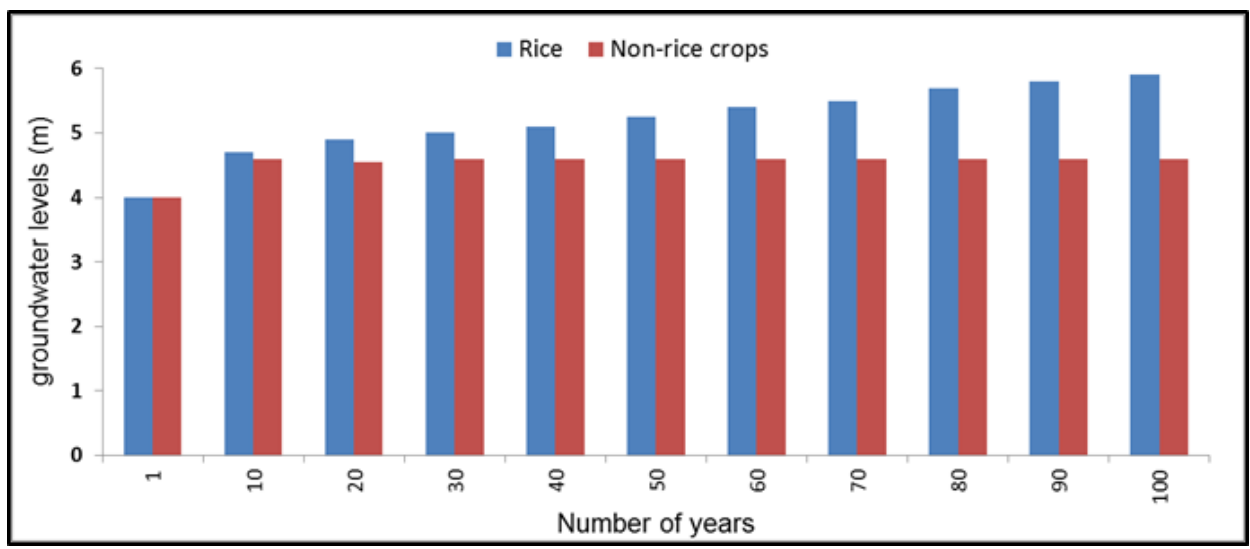

Figure 6. Comparison between GWL for the cultivation of rice and non-rice crops.

\subsection{Assessing the Effect of Changing the Crop Pattern on Soil Salinity}

Increasing irrigation water, according to the plant's needs, improved soil salinity. In this study, a number of non-rice crops were proposed as alternatives to rice due to the reduction of surface water. Table 4 shows the change in the salinity of different crops over time. The selected crops in the table differ in their water consumption. Grapes have the lowest consumption, with water demands of $4.55 \mathrm{~mm} /$ day as an average value, while the water demands of rice are the largest, at $7.80 \mathrm{~mm} /$ day as an average value. Salinity increased with respect to time for less water-heavy crops, such as grapes (a non-rice crop), while increasing the water consumed by crops, thereby reducing the soil salinity, wherein the crops that consumed significant amounts water (rice crops) provided less soil salinity over 50 years. 
Table 4. Soil salinity for different crops.

\begin{tabular}{cccccc}
\hline \multirow{2}{*}{ Year } & \multicolumn{5}{c}{ Salinity (S/m) } \\
\cline { 2 - 6 } & Grapes & Squash & Melons & Maize & Rice \\
\hline one & 0.44 & 0.44 & 0.44 & 0.44 & 0.44 \\
5 & 0.44 & 0.44 & 0.44 & 0.44 & 0.44 \\
10 & 0.45 & 0.44 & 0.44 & 0.44 & 0.44 \\
20 & 0.45 & 0.44 & 0.44 & 0.44 & 0.44 \\
30 & 0.46 & 0.45 & 0.45 & 0.45 & 0.45 \\
40 & 0.47 & 0.45 & 0.45 & 0.45 & 0.45 \\
50 & 0.48 & 0.45 & 0.45 & 0.45 & 0.45 \\
\hline
\end{tabular}

When cultivating grapes, which consumes the least amount of water compared to other crops, a remarkable increase in soil salinity by time is observed (Figure 7). The trend line of this relationship is expressed in five types of equations (Table 5), in spite of their different values. However, all of them are greater than 0.7, which is a sign of strong relationships. Equation (2) is a second-degree equation and illustrates that salinity is a function of time and directly proportional to time. Thus, resorting to cultivating plants and consuming a smalleramount of surface water are considered factors that increase the soil salinity over time, taking into account the accumulation of salts and preventing leaching, which is implemented subjectively by crops that consume large amounts of water. Equation (2) could be used in the areas cultivated by plants that consume a small amount of water.

$$
Y=0.0008 x^{2}+0.0001 x+0.4386
$$

where, $\mathrm{x}$ is the time, and $\mathrm{Y}$ is the salinity

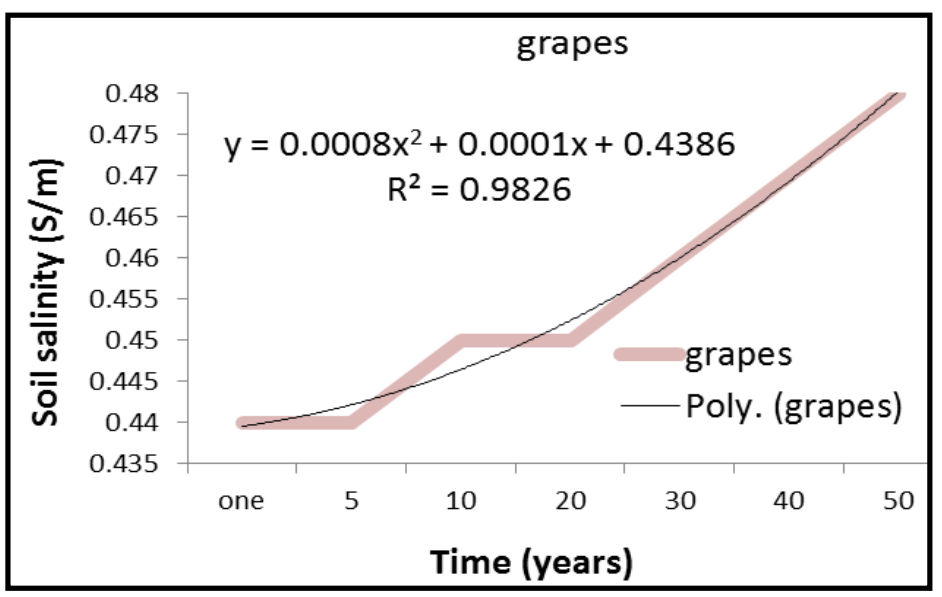

Figure 7. The trend line, correlation factor, and the equation of the relationship between soil salinity for grapes.

Table 5. The portable equations and their correlation factors.

\begin{tabular}{ccccccc}
\hline Equation Type & Exponential & Linear & Logarithmic & Polynomial & Power & Ave. \\
\hline Correlation factor & 0.9437 & 0.9401 & 0.7742 & 0.9824 & 0.7816 & 0.8844 \\
\hline
\end{tabular}

\section{Discussion}

The impact of the three scenarios is summarized in Table 6. According to the results, the GERD could be helpful for Egyptian decision-makers to evaluate current and future situations. This model classifies the type of impact, including negative, neutral, and positive impacts. The score of a negative impact is -1 ; when there is no effect of the GERD on the factor, the score is considered 0 (no impact), 
but to improve the measured factor, the impact is estimated as a positive impact and scored by +1 . The simulation of the effects of a shortage of surface water on GWL showed that there is a strong relationship between both surface water and groundwater. The reduction in surface water would affect the GWL; therefore, the score of the impact could be negative and is expressed in Table 3 by the value of -1 .

Table 6. The effects of the Grand Ethiopian Renaissance Dam (GERD).

\begin{tabular}{cccc}
\hline The Potential Impact on & \multicolumn{3}{c}{ Effects } \\
\cline { 2 - 4 } & $-\mathbf{1}$ & $\mathbf{0}$ & $\mathbf{1}$ \\
\hline GWL due to a reduction in surface water & $*$ & & \\
GWL due to the cultivation of voracious crops & $*$ & & \\
GWL due to the cultivation of non-voracious crops & $*$ & \\
Soil Salinity & $*$ & \\
\hline
\end{tabular}

The impact of cultivating voracious crops on GWL showed that there is a strong relationship between both the consumed surface water and the GWL. Under the cultivation of voracious crops, the GWL increased by time. Thus, reducing the cultivation of voracious crops in the Nile Delta could affect GWL negatively. The score of this impact could also be -1 when replacing voracious crops with other crops when the correlation factor exceeds 0.9 . The cultivation of non-voracious crops reduced the GWL. Although the impact was moderate, it still had a negative impact; therefore, the score is -1 . The simulation of the effects of the shortage of surface water on soil salinity showed that there is a strong relationship between soil salinity and the water consumed by plants. For plants that consumed less water, salinity increased with time (such as with grapes), so the impact was also negative.

\section{Conclusions}

Some development projects in some countries may have a severe effect on other countries, such as the effects of dams on shared river basins. The Grand Ethiopian Renaissance Dam (GERD) on the River Nile could affect the surface water and groundwater in Egypt, as a number of previous studies reported. Therefore, assessing the potential impacts of the GERD on Egypt has become necessary. This study presents an assessment of the potential impact of constructing the GERD on the SWL, the GWL in the shallow aquifer, changing the crop pattern, and soil salinity. Several scenarios have been studied to assess this impact. The different scenarios studied by MODFLOW showed that the GERD will affect water resources in Egypt, where the GERD reduces GWL markedly and is considered the second source of water in many sectors in Egypt. There is a strong relationship between GWL and SWL by a correlation factor of up to 0.99 . The GWL decreased from $5 \mathrm{~m}$ to $2 \mathrm{~m}$ by reducing SWL by $50 \%$ in some areas. However, the adopted policy applied by Egypt to reduce the consumption of surface water to overcome the effects of the GERD also reduced GWL when changing the crop patterns in such areas. Cultivation of rice increases the recharge, and GWL could increase with time, while the cultivation of non-rice crops decreased GWL to $4.60 \mathrm{~m}$. The difference between GWL in these two cases increased with time to $0.10 \mathrm{~m}$ after 10 years and to $1.30 \mathrm{~m}$ after 100 years. Hence, the operation of the GERD will affect the second source of water in Egypt from an early stage, and the effects will increase with time. The policy of changing crop patterns not only affects GWL but also extends to changing soil properties. The simulations concluded that crops consuming less water (such as grapes) could increase their soil salinity over time, where soil salinity experiences a minor increase after ten years of cultivation, in contrast to the scenarios of other crops. Soil salinity increased from $0.44 \mathrm{~S} / \mathrm{m}$ to $0.45 \mathrm{~S} / \mathrm{m}$ and reached $0.45 \mathrm{~S} / \mathrm{m}$ after 30 years of simulation. Thus, crop patterns are very important for preventing the degradation of soil quality in Egypt.

The GERD has a clear effect on downstream countries, such as Egypt, especially at the end of the irrigation network in the Egyptian Delta, where our case study is located. The GERD affects GWL by reducing SWL and changing the crop patterns through cultivating non-voracious crops. Not only 
the quantities of surface water and groundwater but also the soil quality will be damaged over time as a result of salt accumulation. On a large scale, these effects are classified as near economic crises in Egypt: A shortage of surface and groundwater, a decrease in soil quality, and reducing the area cultivated by economic crops-such as rice and maize-could affect the Egyptian economy.

Author Contributions: Conceptualization, M.Z.; methodology, S.A.A.; validation, H.A.-E.; formal analysis, P.M.; investigation, S.A.A.; resources, P.P.; data curation, P.P.; writing-original draft preparation, S.A.A.; writing-review and editing, H.A.-E.; visualization, S.A.A.; supervision, M.Z.; project administration, H.A.-E.; funding acquisition, P.M.

Acknowledgments: Thank you for the support of project KEGA 059TUKE-4/2019 M-learning tool for intelligent modeling of building site parameters in a mixed reality environment. This work was supported by the Slovak Research and Development Agency under the contract no. APVV-17-0549.

Conflicts of Interest: The authors declare no conflict of interest.

\section{References}

1. Abdel-Aziz, S.; Negm, A.M.; Abdel-Aal, G.M.; Nassar, M.H. Environmental Impact Assessment of Covering Irrigation Canals Case Study: Abu Kebier City, Sharkia Governorate, Egypt. Ph.D. Thesis, Faculty of Engineering, Zagazig University, Zagazig, Egypt, 2015.

2. Sobeih, M.M.; El-Arabi, N.E.; Helal, E.E.D.Y.; Awad, B.S. Management of water resources to control groundwater levels in the southern area of the western Nile delta, Egypt. Water Sci. 2017, 31, 137-150. [CrossRef]

3. Farrag, A.A. The hydraulic and hydrochemical impacts of the Nile system on the groundwater in upper Egypt. Assuit Univ. Bull. Environ. Resour. 2005, 8, 87-102.

4. Wheeler, K.G.; Basheer, M.; Mekonnen, Z.T.; Eltoum, S.O.; Mersha, A.; Abdo, G.M.; Zagona, E.A.; Hall, J.W.; Dadson, S. Cooperative filling approaches for the grand Ethiopian renaissance dam. Water Int. 2016, 41, 611-634. [CrossRef]

5. Abdelhaleem, F.S.; Helal, E.Y. Impacts of Grand Ethiopian Renaissance Dam on different water usages in upper Egypt. Br. J. Appl. Sci. Technol. 2015, 8, 461-483. [CrossRef]

6. Arby, R.S. The Rejection of Egypt toward Grand Ethiopian Renaissance Dam In Ethiopia (2011-2016); Department of International Program of International Relations Universitas Muhammadiyah Yogyakarta: Bantul, Yogyakarta, 2016.

7. Armanuos, A.M.; Ibrahim, M.G.; Mahmod, W.E.; Negm, A.; Yoshimura, C.; Takemura, J.; Zidan, B.A. Evaluation the potential impact of Grand Ethiopian Renaissance Dam and pumping scenarios on groundwater level in the Nile Delta aquifer. Water Sci. Technol. Water Supply 2017, 17, 1356-1367. [CrossRef]

8. Ramadan, S.M.; Negm, A.M.; Helmy, A. Environmental impacts of Great Ethiopian Renaissance Dam on the Egyptian water resources management and security. In Proceedings of the 23rd International Conference on: Environmental Protection Is a Must, Alexandria, Egypt, 11-13 May 2013.

9. Attalla, R.A. Grand Ethiopian Renaissance Dam (GERD)—An Interactive Qualifying Project Report; Faculty of Worcester Polytechnic Institute: Worcester, MA, USA, 2015.

10. El-Nashar, W.Y.; Elyamany, A.H. Managing risks of the Grand Ethiopian Renaissance Dam on Egypt. Ain Shams Eng. J. 2018, 9, 2383-2388. [CrossRef]

11. Abd-Elhamid, H.F.; Abdelaty, I.; Sherif, M. Evaluation of potential impact of Grand Ethiopian Renaissance Dam on seawater intrusion in the Nile Delta aquifer. Int. J. Environ. Sci. Technol. 2019, 16, 2321-2332. [CrossRef]

12. Abdelaty, I.; Wahid El-Din, O.; Abdel-Aal, G.M.; Sallam, G.A. Environmental Impacts Assessment of Subsurface Drainage Projects in Egypt; Department of Water and Water Structures, Faculty of Engineering, Zagazig University: Zagazig, Egypt, 2010.

13. Zvijáková, L.; Zeleňáková, M.; Purcz, P. Evaluation of environmental impact assessment effectiveness in Slovakia. Impact Assess. Proj. Apprais. 2014, 32, 150-161. [CrossRef]

14. Sharkawi, A. Theory and Implementation of Groundwater Situation and Aquifer Evaluation of Some Localities in Sharkia Governorate, Egypt. Master's Thesis, Geology Department, Faculty of Science, Zagazig University, Zagazig, Egypt, 2008. 
15. Abdel Aziz, S.; Negm, A.M.; Abd-Elhamid, H.F.; Abdel- Aal, G.M.; Nassar, M.H. The impact of irrigation canals covering on groundwater in the Nile delta, a case study: Abu Kebier City, Sharkia, Egypt. Int. Water Technol. J. IWTJ 2009, 5, 57-64.

16. Schlumberger Water Services. Visual Modflow User's Manual. Available online: www.swstechnology.com (accessed on 15 October 2018).

17. Zörb, C.; Geilfus, C.M.; Dietz, K.J. Salinity and crop yield. Plant Biol. 2018. [CrossRef] [PubMed]

18. Jorge, F.S.F.; Xuan, L.; Donald, L.S. Fruit yield and survival of five commercial strawberry cultivars under field cultivation and salinity stress. Sci. Hortic. 2019, 243, 401-410.

(C) 2019 by the authors. Licensee MDPI, Basel, Switzerland. This article is an open access article distributed under the terms and conditions of the Creative Commons Attribution (CC BY) license (http://creativecommons.org/licenses/by/4.0/). 